\title{
Adjustment to the death of a sibling
}

\author{
S A PETTLE MICHAEL AND R G LANSDOWN
}

Department of Psychological Medicine, Hospital for Sick Children, London

SUMMARY Despite the recent increase in interest in terminally ill children and their families and the post death adjustment of parents, there has been little research examining the adjustment and self concept of surviving siblings in such families. This paper discusses the results of a preliminary descriptive study of 28 children (from 14 families) whose brother or sister had died of cancer between 18 and 30 months previously.

Behaviour checklists were completed by parents and teachers and self concept scales administered to the children. A lengthy semistructured interview was carried out, and measures of parental adjustment were gathered.

A high percentage of children were found to be exhibiting emotional or behavioural difficulties, or both, and the results indicated that low self esteem was common. Parental and child adjustment were not found to be related inter se, nor did they seem to relate to the child's self esteem. Thus for many children the loss of a sibling might cause long term distress. Further, many children who did not manifest overt difficulties perceived themselves unfavourably in comparison with either their ideal or their dead sibling.

Previous reports relating to bereaved siblings are scanty and mainly limited to individual case studies and some reports in psychoanalytical publications. ${ }^{1-7}$ An array of emotional and behavioural sequelae have been reported, including disturbed ego functioning, poor self concept, guilt laden reactions, death phobias, and character distortions. These reports are, however, predominantly anecdotal, and in view of the lack of systematic research it has been necessary to look at other related areas that are relevant to this topic.

Children in families where there is a chronically or terminally ill child have been extensively studied and have been found to perceive themselves as more socially isolated, ${ }^{8}$ to present management difficulties for their parents, ${ }^{9}$ and to be more prone to adjustment problems, particularly irritability or withdrawal. ${ }^{10}$ Review articles concluded that the incidence of psychiatric disorder reported among the siblings of sick or handicapped children varied from $0 \%-50 \%$ and that the degree of emotional or behavioural disturbance, or both, was thought to be influenced by the nature, severity, duration, and prognosis of the medical condition. ${ }^{11} 12$ In studies where the condition was either leukaemia or solid tumours siblings were consistently reported to experience difficulties coping. Simeonsson and McHale identified the three most common negative effects as being identity problems, increased physical demands, and the surviving child's assumption of responsibility for compensating his parents for the $\mathbb{Q}$ limitations of the sick sibling. Both reviews stressed $\overrightarrow{\vec{P}}$ that positive benefits might also accrue-for $\frac{1}{3}$ example, the development of desired attributes such as tenderness, compassion, and increased maturity. In a recently reported study of the siblings of autistic and diabetic children those in the autistic group were found to have the highest rating of social : competence and lowest mean scores for external- $\underline{3}$. ising behaviour problems compared with the siblings $\delta$ of either diabetic or healthy children. ${ }^{13}$

There is a wealth of reports discussing the effects 0 on parents of losing a child, but only recently has any systematic attempt been made to define or measure family adjustment in the period after bereavement. Spinetta et al used criteria derived $\overparen{N}$ from observations made in earlier work to devise a $N$ semistructured interview that could be rated to N determine a measure of adaptation. ${ }^{14}$ The criteria ${ }_{\sigma}$ included general malaise, an inability to return to normal functioning, continued apathy and feelings of sadness, and an inability to confront reminders of $\stackrel{\Phi}{\mathcal{Q}}$ the child and to plan for the future. Among the 23 families interviewed three factors were found to be predictive of good post death adjustment: the $\overrightarrow{\mathbb{Q}}$ availability of on going support from a 'significant $\frac{}{\mathbb{D}}$ 
other'; the adherence to a philosophy of life within which the diagnosis and its implications could be accepted; and an awareness that the deceased child had received information and emotional support at a level consistent with its questions, age, and stage of development. Despite the fairly good adjustment in some families, many parents reported unresolved feelings and symptoms in surviving siblings up to three years after the death. May and Breme devised a self report scale using similar criteria, adding the parents' perception of available support and/or ability to use it, and the receipt of sufficient accurate information about the child's condition. ${ }^{15}$ These two studies have taken a crucial step towards defining and assessing family adjustment, but as yet neither measure is sufficiently researched to produce reliable results.

Children bereaved of a parent have been found to be more likely to develop psychiatric disorders in both child- and adulthood than children from intact homes, ${ }^{16-18}$ and there have been papers suggesting ways in which such children's adaptation to loss might be encouraged. ${ }^{19-21}$ Methods most often mentioned are allowing children to express their feelings of anger and loss and helping them towards an understanding of death as an end to bodily functions in concrete terms, while reassuring them that it is not the result of a wish or hostile thinking. Many authors cite the value of preparing the child for impending loss of the parent and suggest that a previous experience of death (even of a family pet) may help a child to cope. There has also been an emphasis on maintaining a stable environment and on providing experiences that afford the child a sense of closure-for example, 'saying goodbye', attending the funeral, being allowed to have some of the deceased's belongings. Similar suggestions are made with regard to children who face the death of a sibling, but as yet no study has determined which of these experiences are beneficial or otherwise.

\section{Current study}

Subjects. A total of 31 families was identified through hospital records as fulfilling the following criteria:

(a) patient's death between 18 and 30 months previously:

(b) patient aged 2 years or more:

(c) surviving siblings aged between 5 and 21 years:

(d) parents neither divorced nor separated;

(e) no other handicapped or seriously ill child in the family.

Of the 31 families approached, 14 agreed to participate, the number of children in these families being
28 in total. Their ages ranged from 5 to 21 years, the ages of the deceased children from $2 \frac{1}{4}$ to $14 \frac{1}{2}$ years. The number of siblings of the same sex was 11 , and the maximum age difference between the deceased and surviving sibling was 7 years. The length of the deceased child's illness-that is, from date of diagnosis to death-varied from seven days to 148 months.

Method. The families were interviewed in their own homes using a semistructured interview schedule to obtain details of the child's illness and death, to discuss their effects on the surviving child(ren), and to gather the parents' observations as to the effect on the family as a whole. The following measures were used:

\section{(1) Self concept scale 22}

This is a simple paper and pencil test in which the child rates self in response to a list of characteristics as he or she both is ('self as I am') and would like to be ('ideal self'). The discrepancy between the two is considered to be a measure of the child's satisfaction with him or herself. For this study a third scale of 'my sister/brother as he or she was' was added as a measure of the child's view of the dead sibling.

\section{(2) Rutter child scales 'A' (for parents) and ' $B$ ' (for teachers) ${ }^{23}$}

These are two commonly used behaviour checklists with well established cut off scores indicating significant levels of behavioural or emotional disturbance, or both, in the child being rated.

\section{(3) Malaise inventory ${ }^{2.3}$}

This self report inventory, completed by each parent, relates to emotions and physical states having important psychological components and is known to be a useful indicator of emotional disturbance.

\section{(4) Family questionnaire}

This measure of family adjustment was developed for this research and was derived from the work of Spinetta et al and May and Breme. It consisted of 17 items rated independently by each parent.

\section{Results}

(1) Self concept scale. These results showed children to perceive themselves to be significantly different from both their 'ideal self' $(t=10 \cdot 8, p<0 \cdot(001)$ and their dead sibling $(\mathrm{t}=8.35, \mathrm{p}<0.001)$. The children's perceptions of the dead sibling were found to differ significantly from their 'ideal self' $(t=1 \cdot 84$, $p<0.05)$. An inspection of the raw data showed that in comparing 'self as I am' with either 'ideal self' or 
the sibling the children always rated themselves unfavourably. The ratings of the sibling, however, often exceeded the child's 'ideal self' by many points.

(2) Behaviour checklists. Rutter scale ' $A$ ' scores were available for 21 children, scale ' $B$ ' scores for 26 . The percentages of children scoring above the cut off point on either scale, and thus designated as having appreciable difficulties, are shown in the Table.

Only one child's score exceeded the cut off score on both scales; therefore, 10 children $(43.5 \%$ of the sample) were identified as experiencing appreciable emotional or behavioural difficulties, or both.

The sample size was considered too small to analyse the effects of birth order, social class, or age on self concept measures. The Figure illustrates the age distribution of the sample and the subsample defined by having scores above the cut off point on one or other of the Rutter scales. No significant difference was found between the self esteem scores of children scoring above and below the cut off points. There was a negative correlation $(r=-0 \cdot 346$, $\mathrm{p}=0.05, \mathrm{n}=26$ ) between self esteem scores and duration of illness, suggesting that the shorter the

Table Children scoring above the cut off point on the Rutter behavioural checklists

\begin{tabular}{lll}
\hline & $\begin{array}{l}\text { No of } \\
\text { children }\end{array}$ & $\begin{array}{l}\text { No }(\%) \text { of children } \\
\text { above cul off point }\end{array}$ \\
\hline Scale A (parents) & 21 & $3(14)$ \\
Scalc B (tcachers) & 23 & $8(35)$ \\
\hline
\end{tabular}

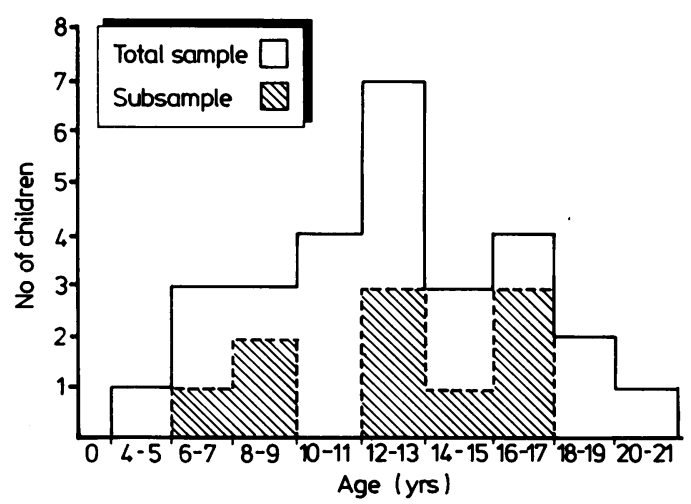

Figure Age distribution of the total sample $(n=28)$ and the subsample defined by having Rutter scale scores above the cut off point $(n=10)$ and thus labelled as suffering from 'psychiatric disorder'. duration of illness the greater the impact on the surviving sibling's view of him or herself.

(3) Family measures. No relation was found between the parental measures of emotional disturbance (Malaise inventory) and the measure of family adjustment. No significant relation was found between the measure of family adjustment and Rutter scale scores, the child's self esteem score, the length of the patient's illness, or the time that had elapsed since the patient's death.

(4) Children's experiences. In the family interviews parents were asked about the prevalence of the events postulated in earlier reports as being helpful in promoting adjustment-that is,

(1) having knowledge of the diagnosis and likely fatal outcome;

(2) participating in the patient's care-for example, visiting regularly;

(3) having the opportunity to 'say goodbye' in the terminal phase;

(4) having the sibling die at home;

(5) seeing the dead body;

(6) attending the funeral or cremation by choice or being included in the family gathering;

(7) being given the patient's possessions;

(8) previously experiencing the death of a close relative or pet.

A point was allocated for each experience, and this score was found to correlate significantly $(\mathrm{r}=-0 \cdot 475, \mathrm{p}=0 \cdot 001, \mathrm{n}=26)$ with self esteem scores obtained for each child. This suggested that children participating in fewer of these events had lower self esteem scores. A highly significant difference was found between the number of facilitative events experienced by children above as against below the cut off points on the Rutter scales $(t=4 \cdot 78, p=0 \cdot 001$, df 26). Four of the children rated as disturbed on the Rutter scales were among the 10 reported by their parents to be unprepared for the fatal outcome of their siblings' illness. Surprisingly, however, it was found that a further four had indeed experienced a high number of 'helpful' events, including having the patient die at home or seeing the dead body, or both.

\section{Discussion}

While this study can be justifiably criticised because of the small sample and the lack of a suitable control group, the picture that emerges merits some attention. There was some indication, from the interview data that were not subject to analysis, that many children had, in the early stages of adjustment, manifested behaviour problems, sleep disturbance, 
and emotional difficulties, which had since disappeared. Clear evidence was available for one child whose school regularly completed the teacher's behaviour checklist on all pupils. Six months after his brother's death one child's score was 14 , but in this study he only scored two. A study of children's responses in a period closer to their bereavement would probably show higher rates of disturbance than reported here.

Among the children in this sample low self esteem was found to be very common and was not restricted to those reported to be manifesting emotional. behavioural. or relationship problems. Further, there seemed to be considerable idealisation of the dead sibling, who was not only perceived by the child as more favourable than 'self as I am' but in many cases the child's own ideal. Thus for many children measuring up to the dead sibling seemed to be an impossible task.

It was this key measure of self esteem, obtained directly from each child, that seemed to be more significantly related to other variables than were the observations of parents or teachers. For example, the surviving child's self esteem was related to the length of the patient's illness. In general, the longer the illness, the happier the children were with themselves. This may be a reflection of the greater opportunity for parents to adapt to their own forthcoming loss and subsequently help their other children to deal with the experience. Self esteem was also found to be related to the child's experience of events thought to facilitate adjustment, including participation in the care of the patient, 'saying goodbye', and attending the funeral service. These experiences in particular may have helped the children to feel that they had done whatever they could to comfort their brother or sister and to adapt their behaviour, so that they felt fewer regrets after the death. Children experiencing more of these events had a higher regard for themselves in relation to their ideal. Similarly, the discrepancy between the child's perception of self and the dead sibling was smaller when a greater number of these facilitative events had been experienced.

Although the self/sibling discrepancy score did not differentiate between children designated as having significant emotional problems and the remainder of the sample, the result was close to reaching significance. This relationship could therefore be further explored, particularly as it may indicate children's feelings of guilt about their own survival and reflect their idealisation of the sibling.

The behaviour checklists identified 10 out of 23 children $(43.5 \%)$ as having sufficient difficulties to warrant attention. Reviews of the published reports ${ }^{11} 12$ have quoted varying figures, suggesting that anywhere between $0 \%$ and $50 \%$ of the siblings of sick children exhibit behavioural or emotional problems, or both. The percentage found in this study was very high, especially when compared with the $6 \cdot 8 \%$ of $10-11$ year olds in the general population whom Rutter et al found to have significant psychiatric problems..$^{23}$ In a more recent study using the same criteria total prevalence rates for boys and girls aged $13-14$ were quoted as $20 \cdot 8 \%$ and $13 \cdot 6 \%$, respectively. ${ }^{24}$ Our sample did not comprise a high number of urban dwelling children; most were in social class III and none was non-white. It included three children who had been involved in criminal activities since their sibling's death and one who had been referred to a child guidance clinic and another to his general practitioner for treatment of severe sleep disturbance and behavioural problems. The high rate of disturbance was probably, therefore, a reflection of the children's experiences.

Children identified by one or other of the Rutter scales tended to differ from the others in one of two ways. Either they comprised most children who among their 'facilitative' experiences saw the patient dead or witnessed the terminal phase of the illness because their sibling had died at home, or alternatively were among the group of children who received no clear knowledge that their sibling was likely to die. Thus some of the experiences thought to have beneficial effects upon children's adjustment may in fact leave the surviving child with difficult memories and emotions to deal with. The family's approach to the death and events surrounding it may be more important than each experience per se, but this would need further investigation.

The five most common problems identified by teachers were the child being often worried, having poor concentration, tending to do things alone, being very restless, and not being liked by other children. These observations match those of Binger et $a l^{3}$ and Cairns et al.

The interviews with parents, often attended by the surviving children, yielded considerable information. In all but two cases, both parents were present. Interviews lasted between two and four hours. Many families, although experiencing intense emotion, commented that they had found it helpful to talk about their child's illness and death.

During the interviews information was gathered regarding changes of address and health problems experienced by the parents. Many stated that they had made a conscious decision to remain in the house in which their child had lived, only two had moved home, and only one of these clearly for emotional reasons. Others reported that they would have felt unable to remain in the house had their child died at home rather than in the hospital. The 
Malaise inventory showed that few parents were suffering from poor health at the time of the interview, but many couples recalled severe health problems in the first year of bereavement.

There were very few changes of employment among the parents, most remaining in the job they had held before their child was diagnosed. The support of employers, both in terms of time off for hospital visits as well as financial and practical help, was often mentioned.

Many parents referred to their dead child as having been 'very special' and took pride in describing what they saw as exceptional qualities of bravery and maturity. No objective measure was taken of the parents' perceptions of their dead child compared with their perceptions of the surviving siblings, but there is some indication that a degree of idealisation is common. A closer look at parents' perceptions may help to clarify one possible source of the surviving siblings' poor self esteem.

The measurement of family adjustment is as yet in its infancy, and no well researched tool is available. No significant differences were found between the family questionnaire and any other variable. The questionnaire may not have been sensitive enough to detect accurately the families' adjustment to loss. Better results might have been obtained by the use of objective ratings on predetermined criteria rather than a self rating questionnaire for completion by the parents themselves.

A prospective longitudinal study enabling the child's emotional state and self perception to be examined concurrently with the diagnosis of a fatal illness in a sibling would seem essential in determining the exact toll that the experience takes of other children in the family.

Another problem in the study was the difficulty of establishing any meaningful control group against which to compare children who had suffered bereavement. It was possible to gather some information on families not willing to participate, but there seemed to be no difference in the levels of parental adjustment between the groups as measured by the family questionnaire. The reasons for low participation seem to relate to the emotional topic of the investigation-some parents felt that their children's involvement in the research might create further upset at a time when feelings were judged to be less raw. In some cases, spouses reported the other to be unable to talk about the bereavement at all.

The difficulties of generalising from a small sample of children are acknowledged, and a study of a larger group is plainly required. Clearly, however, a high percentage of children show overt signs of difficulty, and still more have a low regard for themselves. Bearing in mind that this study sampled children whose loss had occurred more than two years before this investigation and that there are indications that greater difficulties were experienced in the first year, the need for early intervention to help these children is abundantly clear.

\section{Conclusion}

The study illustrates that even two or three years after the death of a sibling a high percentage of children are showing sufficient difficulties to be labelled as warranting psychiatric help on a well researched behaviour scale.

Many children have low self esteem, which seems to be directly proportional to the length of the patient's illness. High self esteem is more likely if the child experiences a greater number of the following events: being apprised of the likely fatal outcome; participating in the patient's care-for example, visiting the hospital regularly, having a small helpful role when the sibling is at home; having the opportunity to 'say goodbye' near the time of death; attending the service or being with the rest of the family on the day of the funeral; being able to have some of the sibling's possessions; and previously experiencing the death of a relative or pet. Two other experiences, the sibling dying at home and seeing the dead body, are of questionable benefit. These were more commonly experienced by children having pronounced emotional or behavioural difficulties. If further studies support these findings it will be possible to advise families more precisely as to how they can minimise potential difficulties.

Family adjustment remains difficult to measure, and there was no support for the hypothesis that parental and child adjustment would be related. This study highlights the importance of children's perceptions of themselves and their world, which is mirrored in the increasing emphasis on cognitive therapy with children. Children cannot be seen as merely 'being on the receiving end' of events or guided by their parents' ability to cope with trauma. Excluding children from information seems to be unsuccessful in reducing their pain, as clearly they sense that something is seriously amiss, and in the absence of age appropriate explanations, are prone to fantasise. Therefore, children must be viewed as people who observe and interact with their environment with their own understanding and appreciation of it.

Further studies of a prospective kind would help to identify those children at greater risk of developing adjustment problems and clarify which experiences are most likely to facilitate adjustment. Interventions enabling children to ventilate their 
sadness and anger as well as their feelings towards themselves and other family members, either within the family or as part of a group, could possibly help to reduce later distress.

Grateful thanks are due to Dr J Pritchard, Dr J Chessells, and members of the Hacmatology/Oncology teams for their cooperation and help and to S L Michacl for editorial help.

\section{References}

1 Cain AC, Fast I, Erickson ME. Children's disturbed reactions to the death of a sibling. Am J Orthopsychiatry 1964:34:741-52.

2 Rosenblatt B. A young boy's reaction to the death of his sister: report based on bricf psychotherapy. J Am Acad Child Psychiatry 1968:8:321-35.

${ }^{3}$ Binger CM, Ablin AR. Fcucrstein RC, et al. Childhood lcukacmia. Emotional impact on patient and family. $N$ Engl $J$ Med 1969:280:414-6.

+ Poznanski EO. The 'replacement child': a saga of unresolved parental gricf. J Pediatr 1972;81:11901-3.

5 Tietz W, McSherry L. Britt B. Family sequelac after a child's death due to cancer. Am J Psychother 1977:31:417-25.

"Berman LEA. Sibling loss as an organizer of unconscious guilt: a case study. Psychoanal $Q$ 1978:47:565-87.

7 Spinetta JJ, Deasy-Spinetta P. Living with childhood cancer. St Louis, USA: C V Mosby Co, 1981

* Cairns NU. Clark GM. Smith SD, Lansky SB. Adaptation of siblings to childhood malignancy. J Pediatr 1979:95:484-7.

"Burton L. (cd). The family life of sick children. London: Routledge and Kegan Paul, 1975.

1" Lavigne JV. Ryan M. Psychological adjustment of siblings of children with chronic illness. Pediatrics 1979:63:616-27.

"Black D. Sturge C. The young child and his siblings. In: Howclls JG, ed. Modern perspectives in the psychiatry of infuncy. London: Oliver and Boyd, 1979:262-83.
12 Simeonsson RJ, McHale SM. Review: research on handicapped children: sibling rclationships. Child Care Health Dev 1981:7:153-71.

1.3 Ferrero M. Chronic illness: psychosocial effects on siblings-I: chronically ill boys. J Child Psychol Psychiatry 1984;25:459-76.

${ }^{14}$ Spinetta JJ. Swarner JA, Sheposh JP. Effective parental coping following the death of a child from cancer. J Pediatr Psychol $1981: 6: 251-63$.

15 May HJ, Breme FJ. SIDS family adjustment scale: a method of assessing family adjustment to sudden infant death syndrome. Journal of Death and Dying. 1982-3;13:59-74.

16 Black D. What happens to bercaved children? Therapeutic Education 1974;2:15-20.

17 Black D. The bercaved child. J Child Psychol Psychiatry 1978:19:287-92.

is Salladay SA, Royal ME. Children and death: guidelines for gricfwork. Child Psychiatry Hum Dev 1981;11:203-12.

11) Wessel MA. A death in the family. The impact on children. JAMA 1975;234:865-6.

21 Torric A. When children grieve. London: Crusc Publication. 1978.

21 Black D. Early help for the bereaved child avoids later problems. Modern Medicine 1979:24:49-52.

22 Lipsitt LP. 1958. A sclf-concept scalc for children and its relationship to the children's form of the manifest anxiety scale. Child Dev 1958:29:463-72.

23 Rutter M. Tizard J. Whitmore K. Education, health and behaviour. London: Longman. 1970.

24 Leslic SA. Psychiatric disorder in the young adolescents of an industrial town. Br J Psychiatry 1974;125:113-24.

Correspondence to Mrs S Pettle Michacl, Scnior Clinical Psychologist. All Saints' Hospital. Chatham, Kent ME4 5NG.

Received 28 November 1985 